\title{
Study on Thermal Conductivity of Thermal Insulation Cement in Geothermal Well
}

\author{
Fengyan Zhang * and Lixin Li \\ Chinese Academy of Geological Sciences, Beijing, China
}

OPEN ACCESS

Edited by:

Yinhui Zuo,

Chengdu University of Technology,

China

Reviewed by:

Wei Xu,

Xi'an Jiaotong University, China

$\mathrm{Jie} \mathrm{Hu}$,

Chengdu University of Technology,

China

*Correspondence:

Fengyan Zhang

zhangfy18@cags.ac.cn

Specialty section: This article was submitted to

Economic Geology,

a section of the journal

Frontiers in Earth Science

Received: 27 September 2021

Accepted: 20 January 2022

Published: 22 February 2022

Citation:

Zhang F and Li L (2022) Study on

Thermal Conductivity of Thermal Insulation Cement in Geothermal Well.

Front. Earth Sci. 10:784245

doi: 10.3389/feart.2022.784245
When geothermal fluid flows to the wellhead along the wellbore, there is a thermal transfer from the high-temperature geothermal fluid to the low-temperature formation. This process can directly lead to the decrease of wellhead temperature and loss of geothermal energy. Even though previous studies have confirmed that reducing the thermal conductivity of cement could validly cut down the heat loss of geothermal fluid, the influence factors of thermal conductivity are limited. In this research, we conducted detailed studies of the influence factors of thermal conductivity and compressive strength for cement. The results show that with the increase of watercement ratio and thermal insulation materials, thermal conductivity and compressive strength decline. Furthermore, curing temperature is another important factor to improve the thermal preservation effect, but the testing temperature has the opposite influence. Based on these results, the present study concluded that porosity, Skeleton ingredients, curing temperature, and test temperature are vital factors for thermal conductivity. This research provides theoretical guidance for increasing the wellhead temperature of geothermal fluid and enhancing the efficiency of geothermal energy.

Keywords: insulation cement, thermal conductivity, geothermal well, insulation material, compressive strength

\section{INTRODUCTION}

Geothermal energy is clean and sustainable and has been widely used for power generation, heating, and farming (Bildirici and Gökmenoğlu, 2017; Wang et al., 2017; Hamm and Metcalfe, 2019; Yang et al., 2021). In recent years, with the increased need for renewable energy, the exploration and utilization of medium-low temperature geothermal resources have been widely developed in China (Ma et al., 2016; Zhao and Fu, 2019). However, the temperature difference between high-temperature geothermal fluid and low-temperature formations results in the temperature in the wellhead being lower than that in the actual reservoir (Hasan and Kabir, 2002). This is unfavorable to the application of geothermal energy, especially for geothermal wells featured by high bottom temperature or lower fluid-production rate (Kanev et al., 1997; Tóth, 2006).

The wellhead temperature of the geothermal fluid is one of the most important parameters to determine the usage modes and applied efficiency for geothermal energy (Kanev et al., 1997; Tekin and Akin, 2011; Zhou and Zhang, 2013; Gorman et al., 2014). Hence, elevating this temperature is vital for the exploration and utilization of geothermal energy. Recently, more and more research has focused on cement sheath, as its great contribution to heat transfer (Yang et al., 2013; Won et al., 2015). Meanwhile, the theory that decreasing cement thermal conductivity can prominently reduce heat loss has been proposed (Ichim et al., 2016, 
TABLE 1 | Composition of Class G cement.

\begin{tabular}{lccccccc}
\hline $\begin{array}{l}\text { Chemical } \\
\text { composition }\end{array}$ & $\mathbf{M g O}$ & $\mathbf{S O}_{3}$ & $\begin{array}{c}\text { Maximum } \\
\text { of total } \\
\text { alkalinity }\end{array}$ & $\mathbf{C}_{3} \mathbf{S}$ & $\mathbf{C}_{\mathbf{2}} \mathbf{S}$ & $\mathbf{C}_{3} \mathbf{A}$ & $\begin{array}{c}\text { Maximum } \\
\text { value of } \\
\mathbf{C}_{\mathbf{4}} \mathbf{A F}+2 \mathbf{C}_{3} \mathbf{A}\end{array}$ \\
\hline Content (\%) & 2.99 & 1.94 & 0.6 & 58.65 & 16.25 & 1.12 & 16.64
\end{tabular}

Ichim et al., 2018; Li et al., 2017; Zhao, 2020). Based on this theory, calculation method and influence factors (e.g., water-cement ratio, testing temperature, and additives) of cement thermal conductivity have been confirmed (Ichim et al., 2018; Won et al., 2015; Fang et al., 2020). These results revealed the change laws of thermal conductivity from macroscopical sight. The study of influencing factors is not comprehensive and the microcosmic mechanisms remain obscure.

This paper aims to confirm the change laws and corresponding microcosmic mechanisms of thermal conductivity for cement. A precisely designed steady-state method was used at the selected representative thermal insulation materials. Based on this research, thermal conductivity, and compressive strength were affected by different influence factors (i.e., water-cement ratio, thermal insulation materials content, curing, and testing temperature) are documented. Combined with the results of microcosmic analysis (Porosity test and scanning electron microscope), a method of interpreting changes in thermal conductivity and compressive strength from microcosmic sights is proposed. The research results could provide a theoretical basis for the effective utilization of geothermal energy.

\section{MATERIAL AND METHODS}

\subsection{Material}

In this study, class $\mathrm{G}$ cement was used as the basic material as it has been commonly used in geothermal wells. Simultaneously, floating beads with a hollow structure and expanded perlite with a honeycomb-like structure were selected as insulation materials. Results of chemical composition and physical properties of Class G cement are shown in Tables 1, 2. The properties of these two thermal insulation materials are shown in Table 3.

\subsection{Methods}

In this research, four different $(0.5,0.55,0.6$, and 0.7$)$ water-cement ratios (w/c ratio) were chosen for pure cement slurry. The mass ratio of thermal insulation materials to Class $\mathrm{G}$ cement is $5 \%, 10 \%$, $15 \%$, and $20 \%$ respectively. Besides, a fixed w/c ratio (0.7) was selected for thermal insulation cement slurry, and water-reducing agents were used in maintaining its rheological properties. The comparison between pure cement with a w/c ratio of $0.7(\mathrm{w} / \mathrm{c}=0.7)$ and thermal insulation cement with different contents of thermal insulation materials was conducted. Meanwhile, the steady-state method was used to accurately calculate the thermal conductivity of cement. The tools designed for making cement samples in this study are shown in Figure 1. During the design process, the ratio between sample diameter and thickness was greater than 8 .

Cement powder and thermal insulation materials were mixed before the thermal insulation cement was made. Then the mixture was poured into a water-bearing agitator with low stirring speed. Meanwhile, the pouring process was completed in $15 \mathrm{~s}$. The slurry was then cured in a curing chamber with curing temperatures of $60^{\circ} \mathrm{C}, 90^{\circ} \mathrm{C}$, and $120^{\circ} \mathrm{C}$ for $24 \mathrm{~h}$, and the curing pressure was set at $10 \mathrm{MPa}$.

After curing, the thermal conductivity of the cement sample was tested by DRPL-III high precision thermal conductivity tester (measuring range $0.001-3 \mathrm{~W} /(\mathrm{m} . \mathrm{K})$, and the measurement accuracy was $1 \%$. In this study, we use "hot plate temperature-cold plate temperature" to represent the test temperature combination. When the hot plate temperature is $70^{\circ} \mathrm{C}$ and the cold plate temperature is $30^{\circ} \mathrm{C}$, it is expressed as "70-30 ${ }^{\circ} \mathrm{C}$." Two conditions were set for analyzing pure cement thermal conductivity. One set the hot plate temperature at $70^{\circ} \mathrm{C}$ with different $\mathrm{w} / \mathrm{c}$ ratios (i.e., $0.5,0.55,0.6$, and 0.7 ) and curing temperature (i.e., $60^{\circ} \mathrm{C}, 90^{\circ} \mathrm{C}$, and $120^{\circ} \mathrm{C}$ ). The other set the curing temperature at $60^{\circ} \mathrm{C}$ with varied $\mathrm{w} / \mathrm{c}$ ratios (i.e., $0.5,0.55,0.6$, and 0.7 ) and hot plate temperatures (i.e., $50^{\circ} \mathrm{C}, 70^{\circ} \mathrm{C}$, and $90^{\circ} \mathrm{C}$ ). Moreover, the analysis of the thermal conductivity of thermal insulation cement was also conducted under two different conditions. One was set the hot plate temperature at $70{ }^{\circ} \mathrm{C}$ with varied content of thermal insulation materials (i.e., $5 \%$, $10 \%, 15 \%$, and $20 \%$ ) and curing temperatures (i.e., $60^{\circ} \mathrm{C}, 90^{\circ} \mathrm{C}$, and $120^{\circ} \mathrm{C}$ ). The other was set the curing temperature at $60{ }^{\circ} \mathrm{C}$ with different w/c ratios (i.e., 5\%, 10\%, 15\%, and 20\%) and hot plate temperatures (i.e., $50^{\circ} \mathrm{C}, 70^{\circ} \mathrm{C}$, and $90^{\circ} \mathrm{C}$ ).

The microstructures of pure cement and thermal insulation cement were observed by using Nova NanoSEM 450 and AxioCam MRc5. YAW-300B automatic pressure testing machine was used to test compressive strength. The maximum test value of this device is $300 \mathrm{kN}$, and the test error is within $1 \%$. During the test, the loading speed was kept at $71.7 \pm 7.2 \mathrm{kN} / \mathrm{min}$. Dry density and the median pore throat size of cement were achieved through AutoPore IV 9505. Test pressure was set at 1.0 $\mathrm{MPa}$, and the chosen test temperature was $20^{\circ} \mathrm{C}$. Rigaku Ultima IV was used to test changes in mineral types and the content of cement. All the equipment was calibrated before use.

TABLE 2 | Physical properties of Class G cement.

Inspection item Density $\left(\mathrm{g} / \mathrm{cm}^{3}\right) \quad \begin{gathered}\text { Specific surface Water-cement ratio } \\ \text { area }\left(\mathrm{m}^{2} / \mathrm{kg}\right)\end{gathered}$

\begin{tabular}{|c|c|c|c|}
\hline \multirow{2}{*}{$\begin{array}{l}\text { Thicking time } \\
\text { (min) }\end{array}$} & \multicolumn{2}{|c|}{$\begin{array}{l}\text { Compressive strength } \\
\text { (MPa)8 } \mathrm{h}\end{array}$} & \multirow{2}{*}{$\begin{array}{c}\text { Thermal conductivity } \\
\left(\mathrm{W} \cdot(\mathrm{m} \cdot \mathrm{K})^{\times 1}\right) \\
70^{\circ} \mathrm{C}, 20 \mathrm{MPa}\end{array}$} \\
\hline & $38^{\circ} \mathrm{C}, 20 \mathrm{MPa}$ & $60^{\circ} \mathrm{C}, 20 \mathrm{MPa}$ & \\
\hline 11 & 2.5 & 12 & 0.896 \\
\hline
\end{tabular}


TABLE 3 | Properties of thermal insulation materials.

\begin{tabular}{|c|c|c|c|c|c|c|c|c|}
\hline $\begin{array}{l}\text { Serial } \\
\text { number }\end{array}$ & Properties & $\begin{array}{l}\text { Density } \\
\left(\mathrm{g} / \mathrm{cm}^{3}\right)\end{array}$ & Type & $\begin{array}{c}\text { Size } \\
\text { (mesh) }\end{array}$ & $\begin{array}{l}\text { Particle } \\
\text { structure }\end{array}$ & $\begin{array}{c}\text { Thermal } \\
\text { conductivity } \\
\left(\mathrm{W} \cdot(\mathrm{m} \cdot \mathrm{K})^{-1}\right)\end{array}$ & $\mathrm{SiO}_{2}(\%)$ & $\mathrm{Al}_{2} \mathrm{O}_{3}(\%)$ \\
\hline a & Floating beads & 0.48 & powder & $40-100$ & hollow & 0.065 & 56 & 32.7 \\
\hline$b$ & $\begin{array}{l}\text { Expanded } \\
\text { perlite }\end{array}$ & 0.43 & powder & $40-100$ & honeycomb & 0.037 & 70 & 15 \\
\hline
\end{tabular}
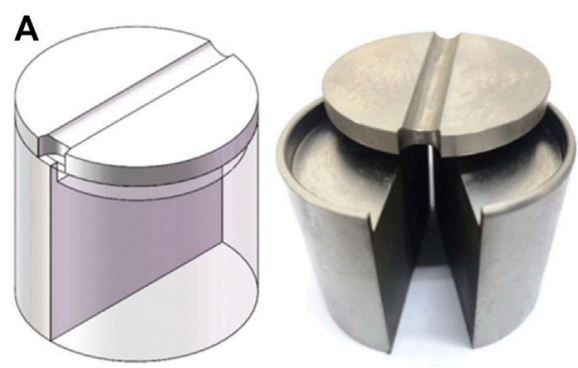

B

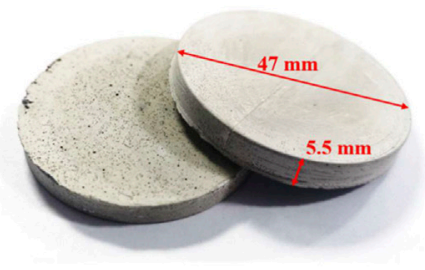

FIGURE 1 | Curing molds and test samples. (A) Curing mold assembly drawing. (B) Thermal conductivity test sample.

\section{RESULTS AND DISCUSSION}

\subsection{Pure Cement}

\subsubsection{Microstructure and Related Parameters}

The microstructure of pure cement under a microscope and scanning electron microscope (SEM) is shown in Figures 2A-D. As the w/c ratio increases from 0.5 to 0.7 , the number and size of primary macropores and micropores in pure cement increases significantly, whereas the per unit volume of small cracks was reduced (Figures 2A-D).

The test results of dry density and the median pore throat radius of pure cement under different $\mathrm{w} / \mathrm{c}$ ratios are shown in Figure 2E. With the increase of $\mathrm{w} / \mathrm{c}$ ratio, the dry density gradually decreases, whereas the median pore throat radius gradually increased (Figure 2E). In a word, the change rates of dry density and median pore throat radius were gradually reduced. That is when the w/c ratio is 0.6 , the dry density and median pore throat radius are $1.37 \mathrm{~g} / \mathrm{cm}^{3}$ and $53 \mu \mathrm{m}$ respectively, accounting for 67.9 and $61.3 \%$ of the total decrease. The increase in the number and size of the primary macropores is the main reason for the changes in dry density and median pore throat radius.

The XRD results of pure cement with different w/c ratios $(0.5$ and 0.7 ) are shown in Figure 3. As shown in the figure, the increase of $\mathrm{w} / \mathrm{c}$ ratio or curing temperature can effectively improve the hydration degree of $\mathrm{C}_{3} \mathrm{~S}, \mathrm{C}_{2} \mathrm{~S}$, and $\mathrm{C}_{4} \mathrm{AF}$, which will result in an obvious increase of $\mathrm{CH}$ and $\mathrm{CSH}$ content (Figures 3A-D).

\subsubsection{Thermal Conductivity}

The thermal conductivity obtained under different curing and hot plate temperatures is shown in Table 4 and plotted in Figures $\mathbf{4 A}, \mathbf{B}$. Notably, as the content of floating beads increases, the thermal conductivity decreases rapidly at first and then the reduction rate becomes relatively slow (Figures $4 \mathbf{A}, \mathbf{B}$ ). The thermal conductivity of pure cement $(\mathrm{w} / \mathrm{c}=0.7)$ is $21.2 \%$, $25.0 \%$, and $25.6 \%$ respectively lower than that of pure cement $(\mathrm{w} / \mathrm{c}=0.5)$ under three different curing temperatures (i.e., $60^{\circ} \mathrm{C}$, $90^{\circ} \mathrm{C}, 120^{\circ} \mathrm{C}$ ) (Figure $4 \mathrm{~A}$ ). In the same case, the decrease percentage is higher than $20.1 \%$ under three different hot plate temperatures (Figure 4B). It is believed that the improvement of the degree of hydration of cement particles and cement porosity are two major factors that lead to the decrease of thermal conductivity. Moreover, as the w/c ratio is lower than 0.55 , most of the added water is involved in the hydration of the cement particles, and a small number of them are used to form pores. In this process, the increased hydration degree of cement particles will convert more $\mathrm{C}_{3} \mathrm{~S}$ and $\mathrm{C}_{3} \mathrm{~A}$ into $\mathrm{CSH}$ with relatively weak heat conduction capacity, which is the main reason for the reduction of heat transfer capacity of cement skeleton (Qomi et al., 2014; Kumar and Mitra, 2021). When the w/c ratio is between 0.55 and 0.6 , the increase rate of cement particle hydration degree gradually decreases, and the increased pores become the main result of the $\mathrm{w} / \mathrm{c}$ ratio increase. In this case, the thermal conduction capacity of air is much lower than that of cement skeleton. Therefore, the increased pores can effectively reduce the cross-sectional area and prolong the path of heat transfer in cement. The above three results are the main way to reduce the pure cement thermal conductivity. When the w/c ratio is higher than 0.6 , the free water required for cement particle hydration reaches saturation, and the main function of increased free water is to improve porosity. However, as the ratio between the subsequently added free water and total volume of cement slurry continues to decrease, the free water that can be distributed per unit volume slurry also continues to decrease. This leads to a slower change rate in porosity and thermal conductivity. 

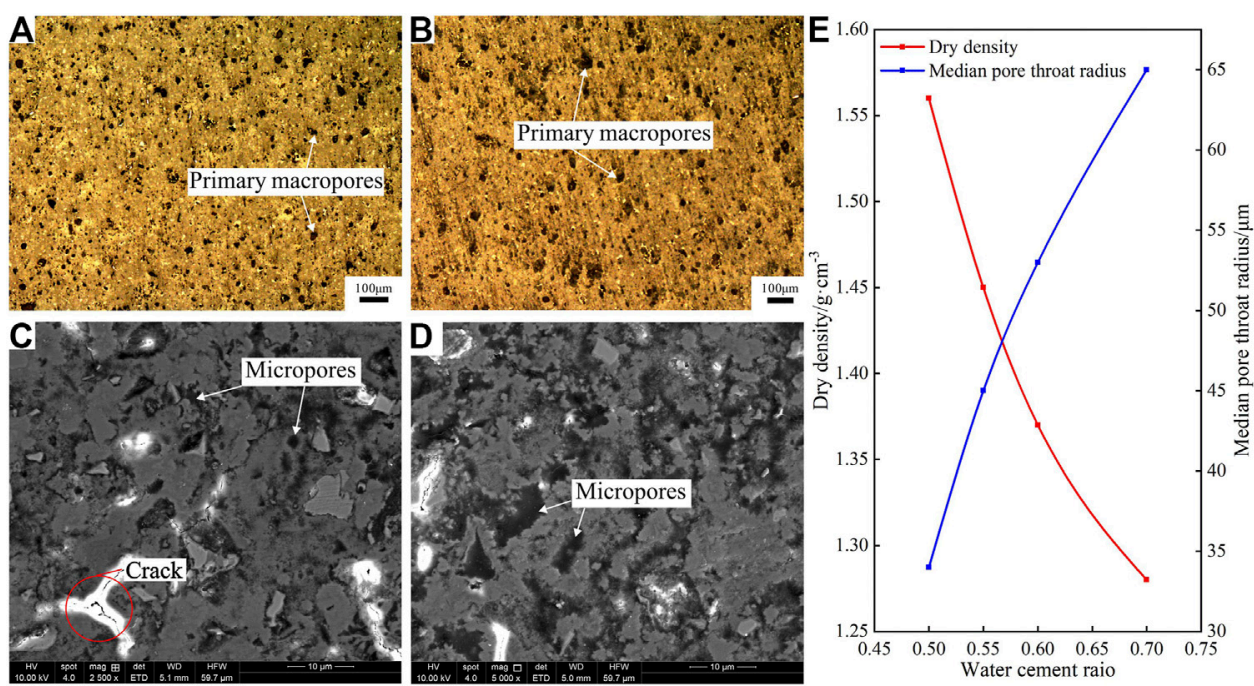

FIGURE 2 | Microstructure and related parameters of pure cement. (A) Microstructure of pure cement (w/c = 0.5) under the microscope. (B) Microstructure of pure cement (w/C = 0.7) under the microscope. (C) Microstructure of pure cement (w/C = 0.5) under SEM. (D) Microstructure of pure cement (w/C = 0.7) under SEM. (E) Dry density and median pore throat radius of pure cement.
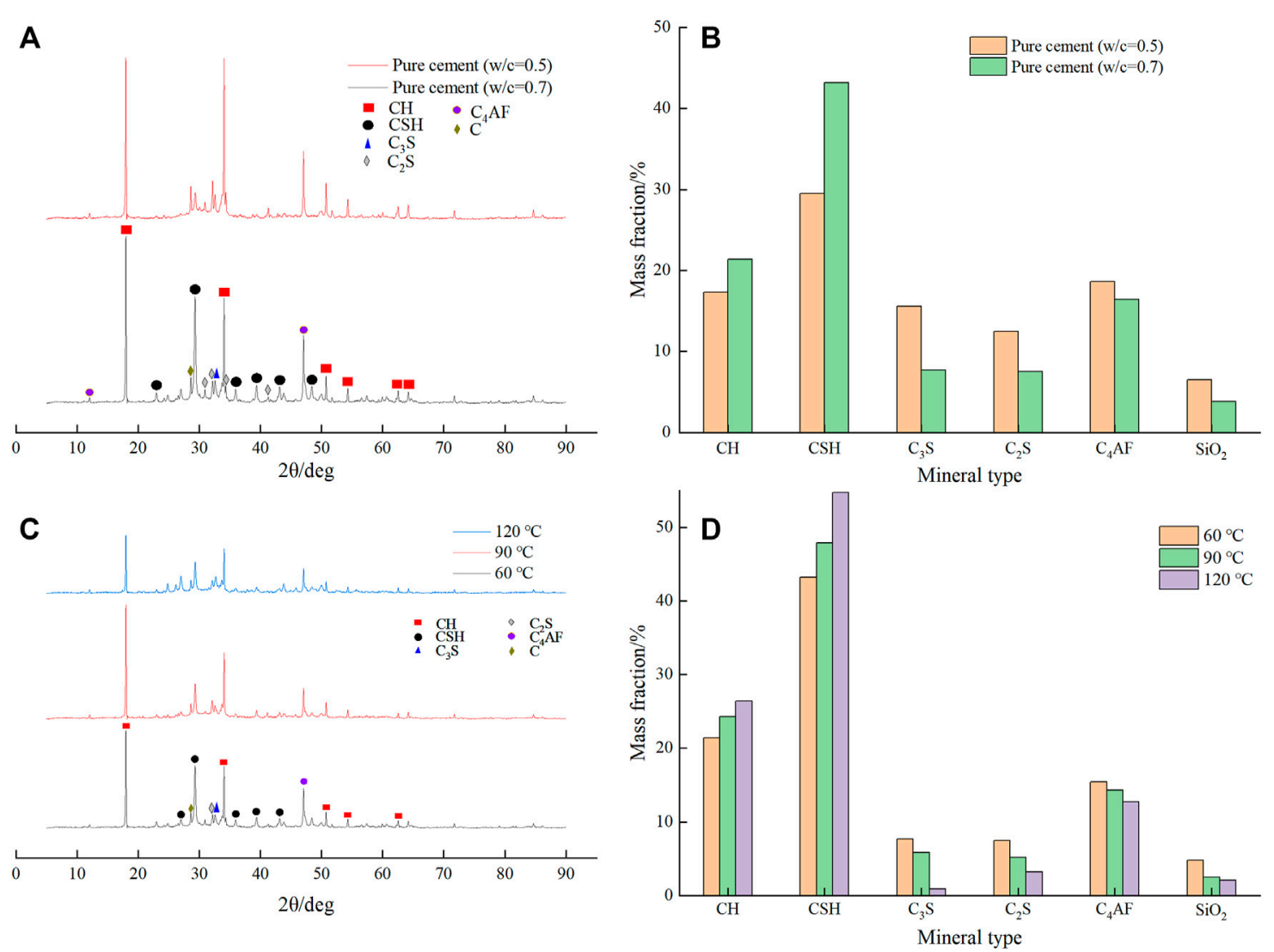

FIGURE 3 $\mid X R D$ test results of pure cement with w/c ratio of 0.5 and 0.7 . (A) XRD results of pure cement with w/c ratio of 0.5 and 0.7 . The curing temperature is $60^{\circ} \mathrm{C}$. (B) Mineral content statistics of Panel (A) results. (C) XRD results of pure cement $(\mathrm{w} / \mathrm{C}=0.7)$ under different curing temperatures. (D) Mineral content statistics of Panel (C) results. 
TABLE 4 | Thermal conductivity and compressive strength of cement.

\begin{tabular}{|c|c|c|c|c|c|c|c|c|c|}
\hline \multirow{3}{*}{$\begin{array}{l}\text { Insulation } \\
\text { material } \\
\text { content (\%) }\end{array}$} & \multicolumn{6}{|c|}{ Thermal conductivity $\left(\mathbf{W} \cdot(\mathrm{m} \cdot \mathrm{K})^{-1}\right)$} & \multirow{2}{*}{\multicolumn{3}{|c|}{$\begin{array}{c}\text { Compressive strength (MPa) } \\
\text { Curing temperature }\left({ }^{\circ} \mathrm{C}\right)\end{array}$}} \\
\hline & \multicolumn{3}{|c|}{ Curing temperature $\left({ }^{\circ} \mathrm{C}\right)$} & \multicolumn{3}{|c|}{ Hot plate temperature $\left({ }^{\circ} \mathrm{C}\right)$} & & & \\
\hline & 60 & 90 & 120 & 50 & 70 & 90 & 60 & 90 & 120 \\
\hline$w / c=0.5$ & 0.909 & 0.880 & 0.863 & 0.872 & 0.909 & 0.948 & 63.9 & 84.3 & 108.8 \\
\hline$w / c=0.55$ & 0.847 & 0.816 & 0.783 & 0.825 & 0.847 & 0.866 & 58.8 & 66.1 & 95.4 \\
\hline$w / c=0.6$ & 0.777 & 0.734 & 0.698 & 0.752 & 0.777 & 0.816 & 45.3 & 60.8 & 87.8 \\
\hline $\mathrm{w} / \mathrm{c}=0.7$ & 0.716 & 0.66 & 0.6423 & 0.696 & 0.716 & 0.757 & 39.2 & 45.0 & 63.9 \\
\hline $5 \%$ floating beads & 0.689 & 0.646 & 0.626 & 0.653 & 0.689 & 0.724 & 29.5 & 45.6 & 45.5 \\
\hline $10 \%$ floating beads & 0.652 & 0.622 & 0.612 & 0.597 & 0.652 & 0.673 & 27.4 & 48.6 & 42.6 \\
\hline $15 \%$ floating beads & 0.611 & 0.585 & 0.571 & 0.557 & 0.611 & 0.636 & 24.7 & 41.2 & 43.6 \\
\hline $20 \%$ floating beads & 0.592 & 0.571 & 0.559 & 0.533 & 0.592 & 0.610 & 22.5 & 38.4 & 45.4 \\
\hline $5 \%$ expanded perlite & 0.693 & 0.625 & 0.611 & 0.642 & 0.693 & 0.712 & 40.5 & 43.8 & 50.8 \\
\hline $10 \%$ expanded perlite & 0.622 & 0.576 & 0.563 & 0.569 & 0.622 & 0.636 & 39.1 & 42.4 & 48.4 \\
\hline $15 \%$ expanded perlite & 0.578 & 0.548 & 0.542 & 0.523 & 0.578 & 0.598 & 36.7 & 42.3 & 46.2 \\
\hline $20 \%$ expanded perlite & 0.565 & 0.534 & 0.532 & 0.503 & 0.565 & 0.575 & 32.9 & 40.0 & 45.5 \\
\hline
\end{tabular}

According to Figure 4A, thermal conductivity significantly reduces as the curing temperature increases. Under the condition of $\mathrm{w} / \mathrm{c}=0.5$ and three different curing temperatures (i.e., $60^{\circ} \mathrm{C}$, $\left.90^{\circ} \mathrm{C}, 120^{\circ} \mathrm{C}\right)$, the thermal conductivity is $0.909 \mathrm{~W} /(\mathrm{mK})$, $0.880 \mathrm{~W} /(\mathrm{mK})$, and $0.863 \mathrm{~W} /(\mathrm{mK})$ respectively. However, as the $\mathrm{w} / \mathrm{c}$ ratio changes to 0.7 , the thermal conductivity decreases to $0.716 \mathrm{~W} /(\mathrm{mK}), 0.660 \mathrm{~W} /(\mathrm{mK})$, and $0.642 \mathrm{~W} /(\mathrm{mK})$ respectively. Therefore, when the curing temperature increases from 60 to $120^{\circ} \mathrm{C}$, the decrease of thermal conductivity is $5 \%(\mathrm{w} / \mathrm{c}$ $=0.5)$ and $10.3 \%(\mathrm{w} / \mathrm{c}=0.7)$ respectively. In summary, it can be determined that the increase in the hydration degree of cement particles and the content of substances with low thermal conductivity, caused by the increase of curing temperature, are the main reasons for the decrease in thermal conductivity.

As shown in Figure 4B, as the hot plate temperatures elevate, the thermal conductivity increases obviously. When the hot plate temperature is increased to $90^{\circ} \mathrm{C}$, the thermal conductivity is
$0.948 \mathrm{~W} /(\mathrm{mK}), \quad 0.816 \mathrm{~W} /(\mathrm{mK})$, and $\quad 0.757 \mathrm{~W} /(\mathrm{mK})$, which correspond with a w/c ratio is $0.5,0.6$ and 0.7 , respectively. These values are $8.6 \%$ higher than that of the hot plate temperature set at $50^{\circ} \mathrm{C}$. The results are mainly attributed to the fact that the improvement of hot plate temperature can enhance the vibration intensity of the heated skeleton. Meanwhile, the convective heat transfer of gas in connecting pores of cement has also been strengthened.

\subsubsection{Compressive Strength}

Compressive strength test results are shown in Table 3 and plotted in Figure 4C. With the increase of w/c ratio, the cement compressive strength decreases apparently. However, it shows an opposite trend to the ascending curing temperature (Figure 4C). As the curing temperature increases gradually, the compressive strength of cement $(\mathrm{w} / \mathrm{c}=0.7)$ is $39.2,45.0$, and $63.9 \mathrm{MPa}$ respectively, which is $38.6 \%, 46.6 \%$, and $41.3 \%$ lower
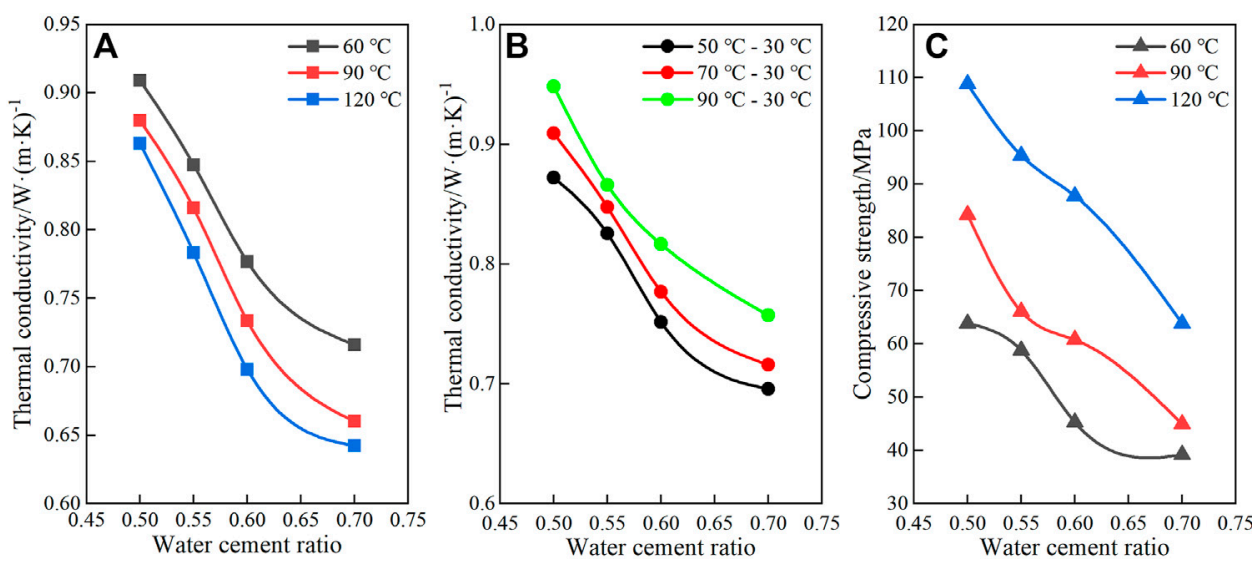

FIGURE 4 | Thermal conductivity and compressive strength test results of pure cement under different conditions. (A) Test results of thermal conductivity at different curing temperatures. The test temperature combination is $70-30^{\circ} \mathrm{C}$. (B) Test results of thermal conductivity at different hot plate temperatures. The curing temperature is $60^{\circ} \mathrm{C}$. (C) Test results of compressive strength at different curing temperatures. 

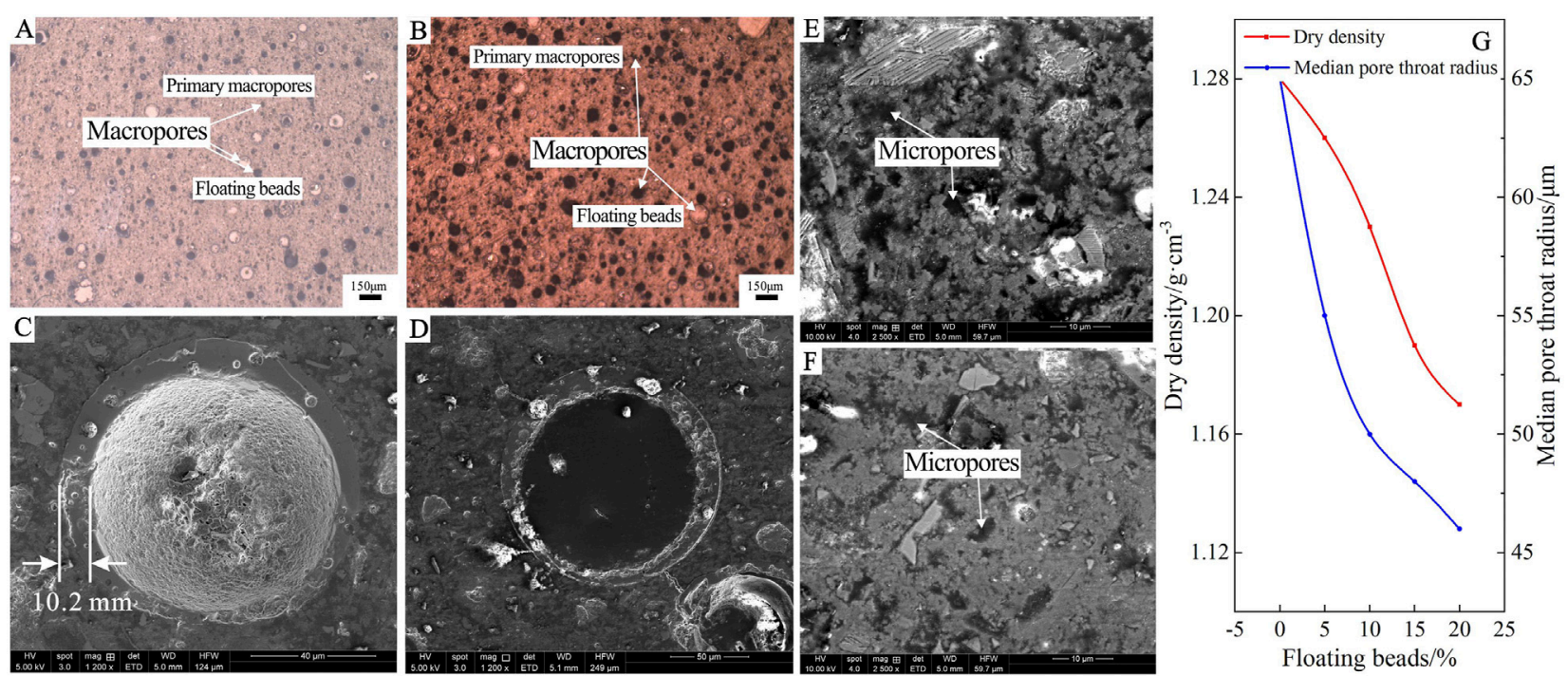

FIGURE 5 | Microstructure and related parameters of thermal insulation cement with floating beads. (A) Microstructure of thermal insulation cement with $10 \%$ floating beads under the microscope. (B) Microstructure of thermal insulation cement with 20\% floating beads under the microscope. (C, D) Microstructure of floating beads under SEM. (E) Microstructure of thermal insulation cement with 10\% floating beads under SEM. (F) Microstructure of thermal insulation cement with $20 \%$ floating beads under SEM. (G) Dry density and median pore throat radius of thermal insulation cement with floating beads.

than that of cement $(\mathrm{w} / \mathrm{c}=0.5)$. Similarly, the compressive strength is $108.8,87.8$, and $63.9 \mathrm{MPa}$, which correspond with $\mathrm{w} / \mathrm{c}$ ratio is $0.5,0.6$, and 0.7 respectively under curing temperature set at $120^{\circ} \mathrm{C}$. These results show that the compressive strength increased $70.3 \%, 93.8 \%$, and $63.0 \%$ compared with the curing temperature set at $60^{\circ} \mathrm{C}$. Analysis shows that the increase in the number and size of primary macropores and micropores is the main reason for the reduction of compressive strength (Figure 2). The increase of curing temperature contributes to the ascending $\mathrm{CSH}$ content. The enhancement of $\mathrm{CSH}$ content is the primary factor leading to the improvement of compressive strength.

The increase of the w/c ratio can effectively improve the size and number of primary macropores and micropores, as well as the hydration degree of cement particles. This can result in the reduction of the heat transfer capacity of the cement skeleton and heat transfer area. However, the heat transfer path appears to have an opposite trend. Similarly, the increase of curing and hot plate temperature can also change the thermal conductivity. Furthermore, the increase in the number and size of primary macropores and micropores is the main reason for the significant decrease in compressive strength.

\subsection{Thermal Insulation Cement With Floating Beads}

\subsubsection{Microstructure and Related Parameters}

The macropores and micropores of the thermal insulation cement are shown in Figures 5A,B,E,F. The microstructure of the floating beads in the cement is shown in Figures 5C,D. Dry density and median pore throat radius are shown in Table $\mathbf{5}$ and plotted in Figure 5G.
Floating beads distribute evenly in the cement (Figures 5A,B). The surface can be closely combined with the cement skeleton, and its hollow structure can effectively replace the skeleton (Figures 5C,D). Increasing the content of floating beads can not only significantly increase the number and size of macropores, but also effectively reduce the number of micropores and increase the density of skeleton (Tylor, 1997; Figures 5A,B,E,F).

The dry density and median pore throat radius decrease as the increase of floating beads. Besides, the reduction rate gradually slows down (Figure 5G). At the same time, most floating beads can stay closed, so there is no effect on the distribution of internal communicating pore in cement. Therefore, the reduction of dry density is mainly attributed to the increase of floating beads. However, the decrease in the size of primary macropores and micropores in the cement leads to a decrease in the median pore throat radius. In addition, the analysis shows that when the content of floating beads is $0-5 \%$, its main function is to replace the primary macropores and compress the micropores. Therefore, the dry density changes are relatively small, whereas the median pore throat radius varies greatly. When the dosage of floating beads changes to $5 \%$, the decreased value of dry density and median pore throat radius accounts for 18.2 and $52.6 \%$ of the total decrease, respectively. As the dosage varies from 5 to $15 \%$, the main function of floating beads further replaces the cement skeleton and compresses the original pores. This will make the reduction rate of dry density changed larger than the median pore throat radius. When the dosage of floating beads reaches $15 \%$, a decrease in dry density and median pore throat particle size account for 81.8 and $89.5 \%$ of the total decrease, respectively. In addition, as the dosage is $15-20 \%$, the ratio of the floating beads to 
TABLE 5 | Dry density and median pore throat radius of cement.

Dry density $\left(\mathrm{g} / \mathrm{cm}^{3}\right)$

Median

pore throat radius $(\mu \mathrm{m})$

$\mathrm{W} / \mathrm{c}=0.5$

$w / c=0.55$

$\mathrm{W} / \mathrm{c}=0.6$

$\mathrm{w} / \mathrm{c}=0.7$

$5 \%$ floating beads

$10 \%$ floating beads

$15 \%$ floating beads

20\% floating beads

$5 \%$ expanded perlite

$10 \%$ expanded perlite

$15 \%$ expanded perlite

$20 \%$ expanded perlite

the total volume of cement slurry is greatly reduced, so the decrease in dry density is also significantly reduced.

The SEM results of floating beads and skeleton in thermal insulation cement are shown in Figures 6A,B. Among them, points of spectrogram 1 and spectrogram 2 are selected from the surface of floating beads, and spectrogram 3 is from the cement skeleton. The XRD results of pure cement $(\mathrm{w} / \mathrm{c}=0.7)$ and thermal insulation cement with $20 \%$ floating beads are shown in Figures 6C,D.

The result of spectrogram 1 can further confirm that mainly two types of oxides i.e., $\mathrm{SiO}_{2}$ and $\mathrm{Al}_{2} \mathrm{O}_{3}$, exist on the surface of float beads. Comparing spectrogram 2 with 3 , it can be found that the calcium content has increased in some areas of the surface of the floating bead. It may be generated by the reaction between oxides and calcium-containing substances in cement slurry (Figures 6A,B). In addition, the research of XRD shows that the addition of floating beads will reduce the content of $\mathrm{Ca}(\mathrm{OH})_{2}$ and increase the content of CSH in cement (Figures 6C,D). This can further support the opinion that the oxides that existed on the surface of the floating beads can react with $\mathrm{Ca}(\mathrm{OH})_{2}$ and form $\mathrm{CSH}$ at the end (Equation 1, 2).

$$
\begin{gathered}
x \mathrm{Ca}(\mathrm{OH})_{2}+\mathrm{SiO}_{2}+\mathrm{mH}_{2} \mathrm{O} \rightarrow x \mathrm{CaO} \cdot \mathrm{SiO}_{2} \cdot m \mathrm{H}_{2} \mathrm{O} \\
y \mathrm{Ca}(\mathrm{OH})_{2}+\mathrm{Al}_{2} \mathrm{O}_{3}+m \mathrm{H}_{2} \mathrm{O} \rightarrow y \mathrm{CaO} \cdot \mathrm{SiO}_{2} \cdot m \mathrm{H}_{2} \mathrm{O}
\end{gathered}
$$

\subsubsection{Thermal Conductivity}

The test results of thermal conductivity for thermal insulation cement with floating beads are shown in Table 4 and plotted in Figures 7A,B. The thermal conductivity gradually decreases with the increase of floating beads. Specifically, the reduction rate of thermal conductivity gradually increases at first, and then gradually decreases (Figures 7A,B). This is similar to the change rule of dry density, as the effect of the floating beads varies under different dosages.

The increased curing temperature can effectively reduce thermal conductivity (Figure 7A). When the curing temperature is $60^{\circ} \mathrm{C}, 90^{\circ} \mathrm{C}$, and $120^{\circ} \mathrm{C}$, the thermal conductivity of thermal insulation cement with $20 \%$ float beads is $0.5922 \mathrm{~W} /$ $(\mathrm{mK}), \quad 0.5713 \mathrm{~W} /(\mathrm{mK})$, and $0.5591 \mathrm{~W} /(\mathrm{mK})$ respectively.
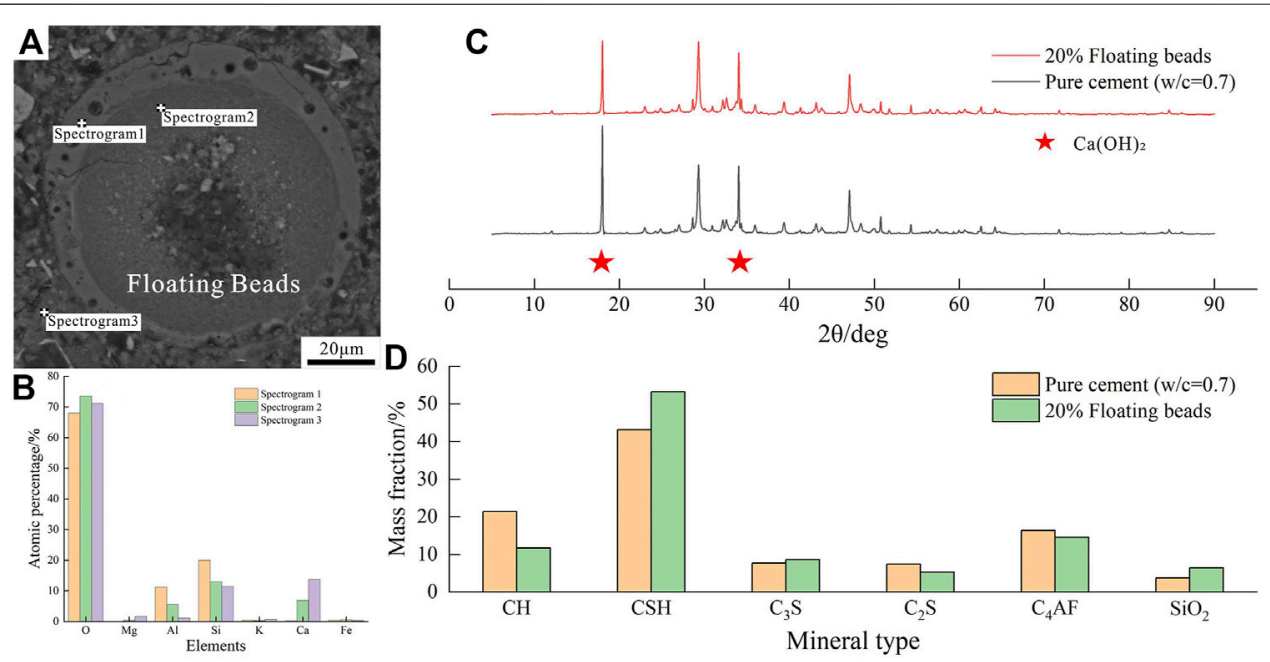

FIGURE 6 | Energy spectrum analysis and XRD results of thermal insulation cement with floating beads. (A) The selected points of spectrograms. (B) Atomic number statistics from energy spectrum analysis results. (C) XRD test results of pure cement (w/C $=0.7)$ and thermal insulation cement with $20 \%$ floating beads. (D) Mineral content statistics of XRD test results. 

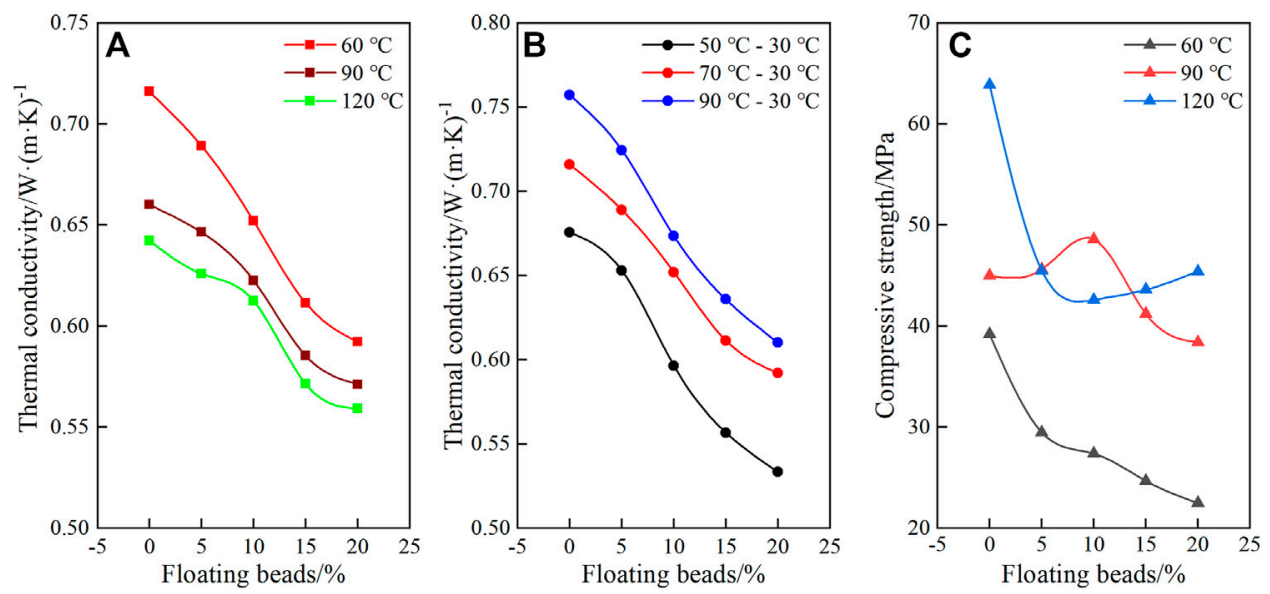

FIGURE 7 | Thermal conductivity and compressive strength test results of thermal insulation cement with floating beads under different conditions. (A) Test results of thermal conductivity at different curing temperatures. The test temperature combination is $70-30^{\circ} \mathrm{C}$. (B) Test results of thermal conductivity at different hot plate temperatures. The curing temperature is $60^{\circ} \mathrm{C}$. (C) Test results of compressive strength at different curing temperatures.

Compared with pure cement $(\mathrm{w} / \mathrm{c}=0.7)$, the thermal conductivity decreases by $17.3 \%, 13.4 \%$, and $12.9 \%$. In addition, for heat insulation cement with $20 \%$ floating beads, the thermal conductivity reduction rate is 4.5 and $6.1 \%$, respectively, which corresponds with the curing temperatures of $60-90$ and $120^{\circ} \mathrm{C}$. For the thermal insulation cement with $10 \%$ floating beads, as the curing temperature is increased, the thermal conductivity reduction rate is 3.5 and $5.6 \%$. The test results clearly show that the reduction rate of thermal conductivity gradually decreases, which is caused by the increase of curing temperature. The increase of porosity and hydration degree of cement particles are the main factors for the decrease in thermal conductivity.

The thermal conductivity increases with the improvement of the hot plate temperature (Figure 7B). Moreover, the change rules of thermal conductivity at three different hot plate temperatures are the same. The thermal conductivity of thermal insulation cement with 10 and $20 \%$ floating beads is $0.5966 \mathrm{~W} /(\mathrm{mK})$ and $0.5335 \mathrm{~W} /(\mathrm{mK})$ respectively, with the hot plate temperature is set at $50^{\circ} \mathrm{C}$. When the hot plate temperature is increased to $70^{\circ} \mathrm{C}$, the thermal conductivity increase rate is 9.3 and $11.0 \%$, respectively. The increased rate of thermal conductivity is 12.9 and $14.4 \%$ respectively, with the hot plate temperature is set at $90^{\circ} \mathrm{C}$. As the hot plate temperature increases, the increase rate of the thermal conductivity decreases. Based on these results, we can conclude that the increase of hot plate temperature can enhance the convective strength of gas inside the floating beads. This is different from the enhancement of gas flow in the connected pores of pure cement.

\subsubsection{Compressive Strength}

The compressive strength of thermal insulation cement with floating beads is shown in Table 4 and plotted in Figure 7C. An increase in the content of floating beads will reduce thermal conductivity, but the effect of increasing curing temperature is the opposite (Figure 7C). The compressive strength of thermal insulation cement with $20 \%$ floating beads at different curing temperatures (i.e., $60^{\circ} \mathrm{C}, 90^{\circ} \mathrm{C}$, and $120^{\circ} \mathrm{C}$ ) are $22.5,38.4$, and $45.4 \mathrm{MPa}$, respectively, which are $42.6 \%, 14.7 \%$, and $28.9 \%$ lower than pure cement under the same w/c ratio. Furthermore, when the curing temperature is increased to 90 and $120^{\circ} \mathrm{C}$, the increased rate of compressive strength for thermal insulation cement with $20 \%$ float beads is 70.7 and $101.8 \%$. Generally, the compressive strength of thermal insulation cement can be maintained at a relatively high level. Research on the microstructure of cement shows that although the addition of floating beads can effectively reduce the number and size of primary pores, the hollow structure of the floating beads can significantly increase the porosity of the cement. This is the main reason for the decrease in compressive strength. In addition, the strength of floating beads derived from the thicker shell (Figure 5C), and hydration of active substances can effectively enhance the strength of the surrounding cement skeleton. This is an important factor for maintaining high compressive strength.

In summary, the addition of floating beads can effectively reduce the thermal conductivity of cement and maintain its compressive strength. Specifically, the increase in porosity is the main reason for the decrease in thermal conductivity. However, the extension of the heat conduction path and hydration of active substances on the surface of the floating beads are other reasons. Moreover, the increase in hydration degree of cement particles, the thicker shell of floating beads, as well as the increase in strength of the surrounding cement skeleton, are important factors for maintaining the cement compressive strength.

\subsection{Thermal Insulation Cement With Expanded Perlite \\ 3.3.1 Microstructure and Related Parameters}

The analyzed results of macropores and micropores for thermal insulation cement with expanded perlite are shown in Figures $\mathbf{8 A}, \mathbf{B}, \mathbf{E}, \mathbf{F}$. The microstructure of the expanded perlite in the 

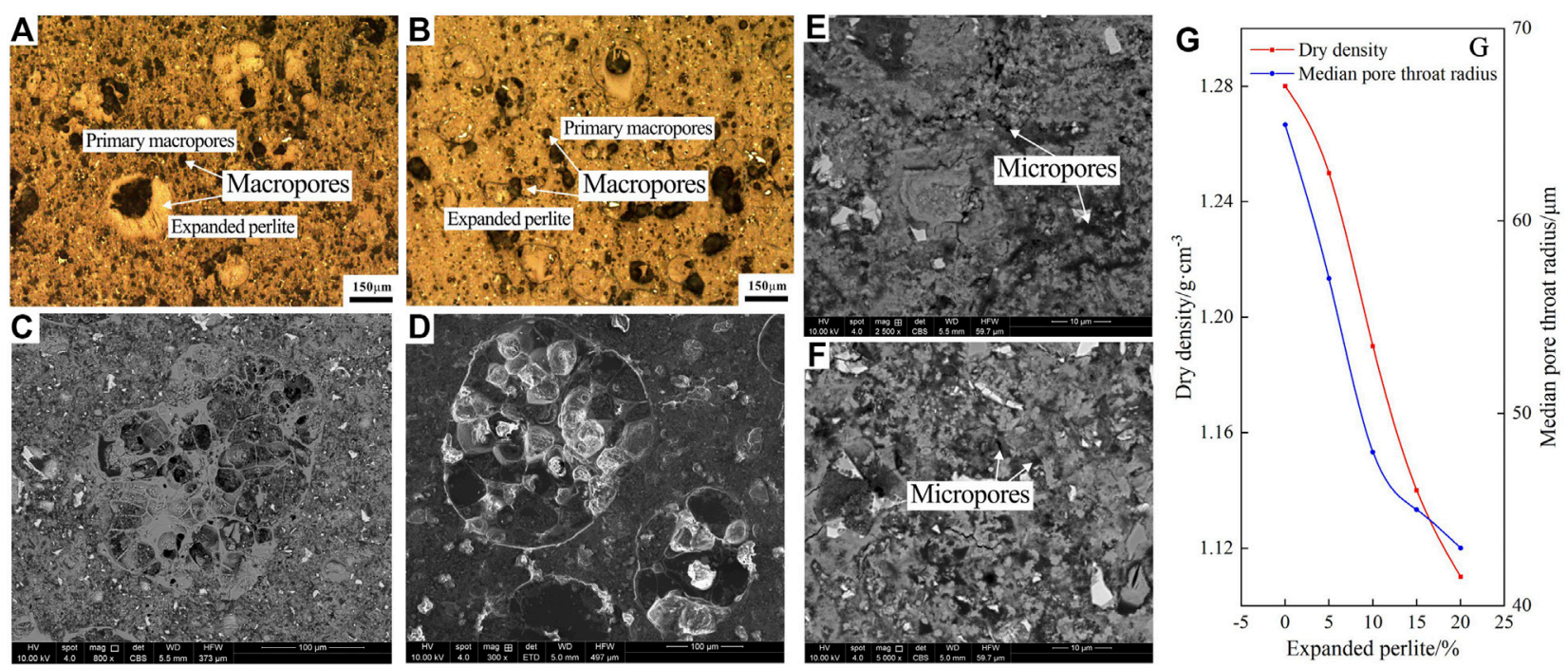

FIGURE 8 | Microstructure and related parameters of thermal insulation cement with expanded perlite. (A) Microstructure of thermal insulation cement with $10 \%$ expanded perlite under the microscope. (B) Microstructure of thermal insulation cement with 20\% expanded perlite under the microscope. (C,D) Microstructure of expanded perlite under SEM. (E) Microstructure of thermal insulation cement with 10\% expanded perlite under SEM. (F) Microstructure of thermal insulation cement with 20\% expanded perlite under SEM. (G) Dry density and median pore throat radius of thermal insulation cement with expanded perlite.

A

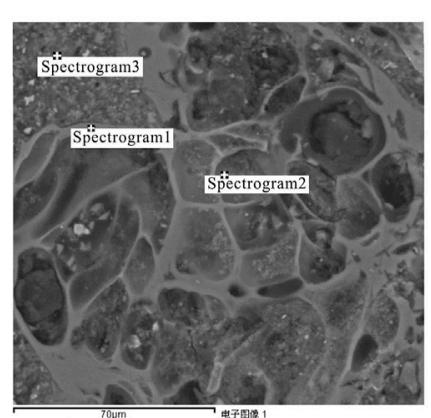

B

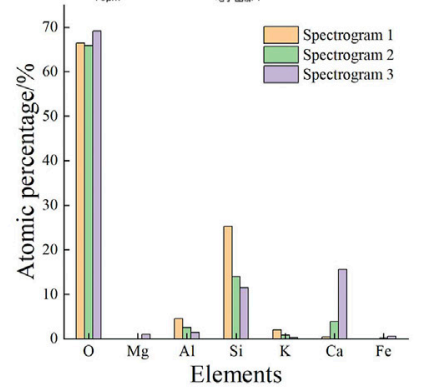

C
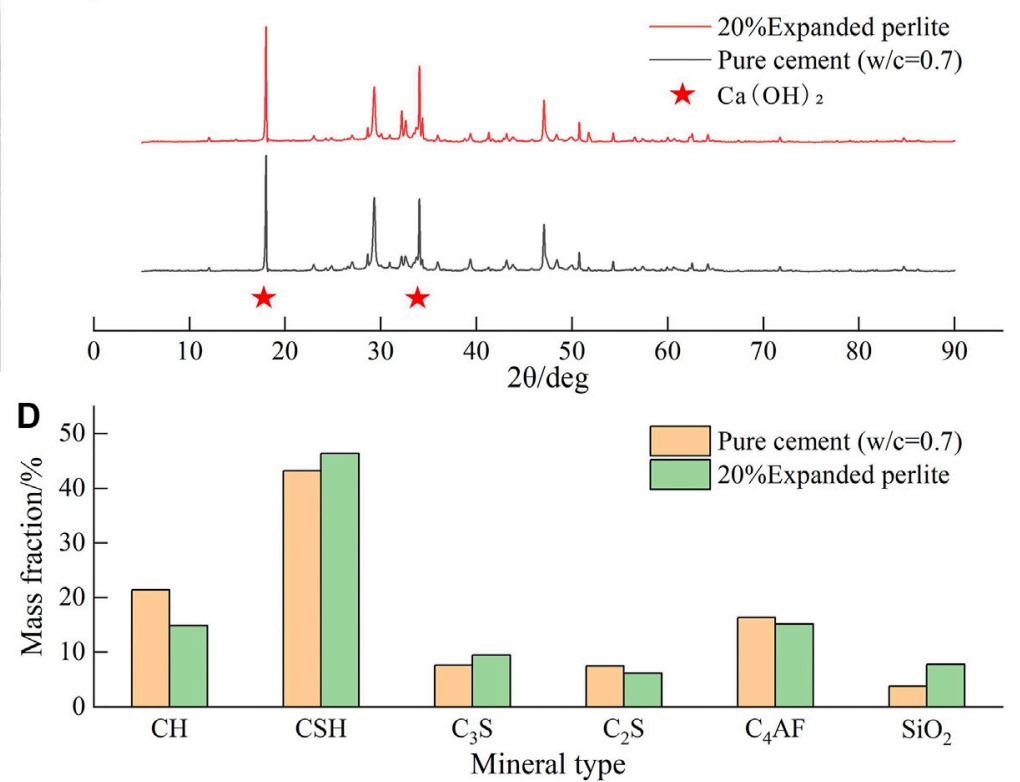

FIGURE 9|Energy spectrum analysis and XRD test results of thermal insulation cement with expanded perlite. (A) The selected points of spectrograms. (B) Atomic number statistics from energy spectrum analysis results. (C) XRD test results of pure cement $(\mathrm{w} / \mathrm{C}=0.7)$ and thermal insulation cement with $20 \%$ expanded perlite. (D) Mineral content statistics of XRD test results. 

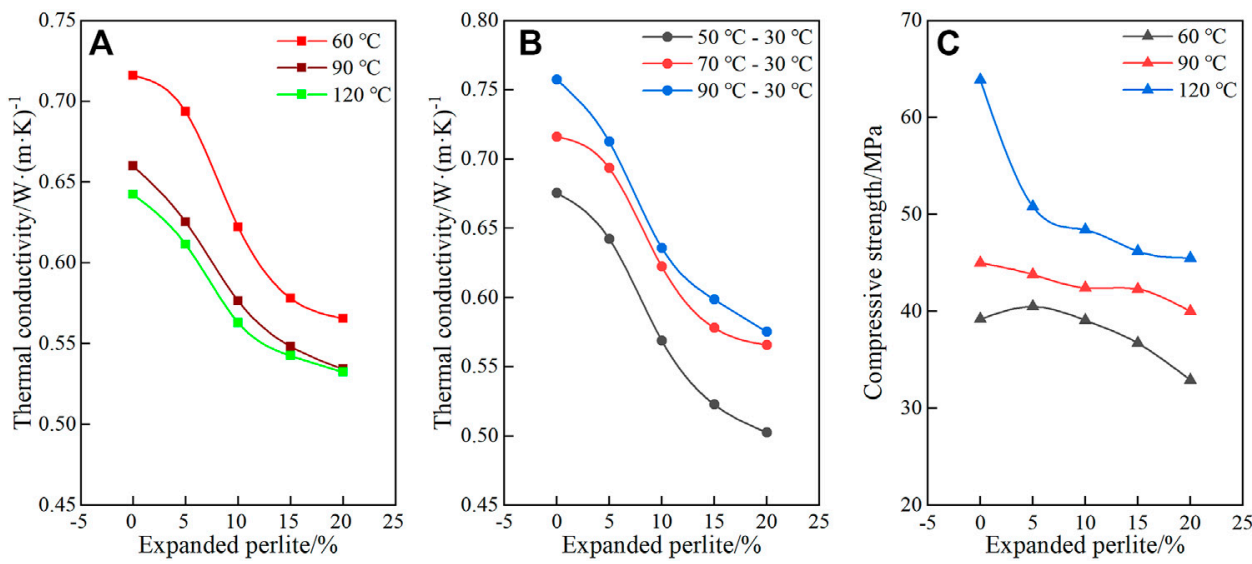

FIGURE 10 | Test results of thermal conductivity and compressive strength of thermal insulation cement with expanded perlite under different conditions. (A) Test results of thermal conductivity at different curing temperatures. The test temperature combination is $70-30^{\circ} \mathrm{C}$. (B) Test results of thermal conductivity at different hot plate temperatures. The curing temperature is $60^{\circ} \mathrm{C}$. (C) Test results of compressive strength at different curing temperatures.

cement under the SEM is shown in Figures 8C,D. Dry density and median pore throat radius are shown in Table $\mathbf{5}$ and plotted in Figure 8G.

The addition of expanded perlite can notably replace the primary macropores and compress micropores. As a result, with the addition of expanded perlite, the number and size of primary macropores and micropores are gradually reduced (Figures 8A,B,E,F). This ultimately leads to the continuous decrease of the median pore throat radius (Figure 8G). Simultaneously, an increase in the expanded perlite content will also significantly reduce the dry density because of its internal honeycomb-like structure (Figures 8C,D,G). When the content of expanded perlite is $10 \%$, the dry density and median pore throat radius is $1.23 \mathrm{~g} / \mathrm{cm}^{3}$ and $50 \mu \mathrm{m}$, and the decreased value under this amount accounts for 45.4 and $78.9 \%$ of the total decrease value. Compared with the thermal insulation cement with floating beads, the cement with expanded perlite has significant advantages for reducing the dry density, and the effect on reducing the median pore throat radius is equivalent.

The SEM results of expanded perlite and skeleton in thermal insulation cement are shown in Figures 9A,B. Among them, points of spectrogram 1 and spectrogram 2 are selected from the surface of expanded perlite, and spectrogram 3 is from the cement skeleton. The XRD results of pure cement $(w / c=0.7)$ and thermal insulation cement with $20 \%$ expanded perlite are shown in Figures 9C,D.

Comparing the results of spectrogram 1, spectrogram 2, and spectrogram 3 , it can be deduced that the main substances that existed on the surface of expanded perlite are $\mathrm{SiO}_{2}$ and $\mathrm{Al}_{2} \mathrm{O}_{3}$, which are similar to floating beads. These oxides can react with $\mathrm{Ca}(\mathrm{OH})_{2}$ in the slurry to form CSH (Figures 9A,B). Eventually, the content of $\mathrm{Ca}(\mathrm{OH})_{2}$ is reduced, and the content of CSH is increased (Figures 9C,D).

\subsubsection{Thermal Conductivity}

The test results of thermal conductivity for thermal insulation cement with expanded perlite at different curing and hot plate temperatures are shown in Table $\mathbf{4}$ and plotted in Figures 10A,B.

In addition to expanded perlite, the thermal conductivity gradually decreases, and the reduction rate increased first and then decreased (Figures 10A,B). This change rule and reasons are identical to that of cement with floating beads. The thermal conductivity of thermal insulation cement with $20 \%$ expanded perlite at a curing temperature of $60^{\circ} \mathrm{C}, 90^{\circ} \mathrm{C}$, and $120^{\circ} \mathrm{C}$ are $0.5656 \mathrm{~W} /(\mathrm{mK}), \quad 0.5343 \mathrm{~W} /(\mathrm{mK}) \quad$ and $\quad 0.5436 \mathrm{~W} /(\mathrm{mK})$, respectively, which are $21.0 \%, 19.0 \%$, and $17.1 \%$ lower than that of pure cement with a w/c ratio of 0.7 (Figure 10A). Similarly, under three different hot plate temperatures, the thermal conductivity of thermal insulation cement with $20 \%$ expanded perlite has a reduced rate of larger than $21 \%$. Combined with the analyzed data, the thermal conductivity of thermal insulation cement with expanded perlite is generally lower than that of cement with floating beads. This may be caused by the relatively small density of expanded perlite. Therefore, with the same mass fraction addition, the amount of expanded perlite that can be added to the cement slurry is much more. Furthermore, the honeycomb-like structure in the expanded perlite is another factor. This structure is more effective in reducing fluid convection in the insulation material (Table 3 and Figure 8C).

The thermal conductivity decreases with the increase of curing temperature (Figure 10A). This can be attributed to an increase in the hydration degree of cement particles and surface oxides of expanded perlite. The thermal conductivity of thermal insulation cement with $10 \%$ expanded perlite can be reduced by 7.3 and $9.5 \%$ when the curing temperature is $60-90^{\circ} \mathrm{C}$ and $120^{\circ} \mathrm{C}$, respectively. Under the situation with the expanded perlite content is $20 \%$, the reduction rate is 5.5 and $5.9 \%$.

Similarly, the thermal conductivity increases with the increase of the hot plate temperature. The higher the temperature, the lower the growth rate. The thermal conductivity of thermal insulation cement with $20 \%$ expanded perlite can be increased by 12.5 and $14.4 \%$ when the hot plate temperature is $50-70^{\circ} \mathrm{C}$ and $90^{\circ} \mathrm{C}$, respectively. 


\subsubsection{Compressive Strength}

The test results of compressive strength for thermal insulation cement with expanded perlite are shown in Table 4 and plotted in Figure 10C. With the addition of expanded perlite, the compressive strength gradually decreases. The results indicate that the increase of curing temperature can significantly enhance the cement compressive strength (Figure 10C). When the content of expanded perlite is $20 \%$, the compressive strength at different curing temperatures (i.e., $60^{\circ} \mathrm{C}, 90^{\circ} \mathrm{C}$, and $120^{\circ} \mathrm{C}$ ) are $32.9,40.0$, and $45.5 \mathrm{MPa}$, respectively. In general, the compressive strength of thermal insulation cement with expanded perlite can maintain a high value under the above test conditions, especially higher than that of cement with floating beads. This may be caused by the relatively higher $\mathrm{SiO}_{2}$ content on the surface of the expanded perlite. It can effectively increase the skeleton strength around the expanded perlite and reduce the possibility of stress concentration. Moreover, the existence of the honeycomb-like structure can greatly improve the plasticity of the cement skeleton, and finally improve the compressive capacity (Figures 8C,D).

In a word, with the addition of expanded perlite and floating beads, thermal conductivity and compressive strength have similar varied trends and mechanisms. However, the honeycomb-like structure inside the expanded perlite is favorable to obtain lower thermal conductivity and maintain the higher compressive strength of cement.

\section{CONCLUSION}

This paper has introduced a steady-state test method. The thermal conductivity and compressive strength of cement under different conditions were tested. The microscopic mechanism of the thermal conductivity and compressive strength change were also explained. The conclusions are as follows:

1) The use of thermal insulation materials can effectively reduce the thermal conductivity of cement and maintain its compressive strength. Specifically, the increase of w/c ratio, thermal insulation material, and curing temperature can significantly reduce cement thermal conductivity. However, the first two factors and the last factor have opposite effects on the compressive strength. Furthermore, the increase in hot plate temperature will increase thermal conductivity. In comparison, the effect of expanded perlite is better than that of floating beads.

2) The increase of porosity and hydration degree of cement particles can effectively reduce the heat transfer area and heat transfer capacity of the skeleton. They are the main reasons for the decrease in thermal conductivity. The

\section{REFERENCES}

Bildirici, M. E., and Gökmenoğlu, S. M. (2017). Environmental Pollution, Hydropower Energy Consumption and Economic Growth: Evidence from G7 Countries, Hydropower Energy Consumption and Economic Growth: Evidence from G7 Countries. Renew. Sust. Energ. Rev. 75 (C), 68-85. doi:10.1016/j.rser.2016.10.052 extension of the heat transfer path and hydration of active substances on the insulation material surface can effectively reduce the thermal transfer efficiency of the skeleton, which are other reasons for the decrease of thermal conductivity. In addition, the hydration of cement particles is the basis for cement to maintain the necessary compressive strength. The strength of the insulation material, the hydration of the surface-active substance, and the internal honeycomb-like structure are important factors to maintain the compressive strength at a high level.

3) Combined with the actual conditions of the formations and engineering, the lower formation temperature of the upper well section will result in a relatively low curing temperature and a relatively large temperature difference (between the hot water and formations) during the pumping process. This will result in a relatively high thermal transfer capacity of cement in the upper well section, and thus this area is the main thermal loss area.

\section{DATA AVAILABILITY STATEMENT}

The original contributions presented in the study are included in the article/supplementary material, further inquiries can be directed to the corresponding author.

\section{AUTHOR CONTRIBUTIONS}

FZ wrote the manuscript and is responsible for providing overall idea, experimental design, and data analysis, LL is responsible for instrument operation. All authors approve the article for publication.

\section{FUNDING}

This work was financially supported by the National Key Research and Development Program of China (Grant No. 2019YFB1504102) and a project of the Chinese Academy of Geological Sciences (Grant No. JKY202008).

\section{ACKNOWLEDGMENTS}

We thank the editor, associate editor, and reviewers for their constructive comments, which helped greatly improve the paper.

Fang, Y., Zhang, Y., and Ran, Z. Z. (2020). Thermal Conductivity of Cementing Conductive Cement in Medium and Deep Geothermal Well. Mater. Rep. 34 (20), 32-37+56. doi:10.11896/cldb.19030004

Gorman, J. M., Abraham, J. P., and Sparrow, E. M. (2014). A Novel, Comprehensive Numerical Simulation for Predicting Temperatures within Boreholes and the Adjoining Rock Bed. Geothermics 50, 213-219. doi:10. 1016/j.geothermics.2013.10.001 
Hamm, S., and Metcalfe, E. (2019). Harnessing the Heat beneath Our Feet: Geothermal Energy. Front. Young Minds 7, 105. doi:10.3389/frym.2019.00105

Hasan, A. R., and Kabir, C. S. (2002). Fluid Flow and Heat Transfer in Wellbores. Texas: Society of Petroleum Engineers, 64-73.

Ichim, A., Teodoriu, C., and Falcone, G. (2016). "Influence of Cement Thermal Properties on Wellbore Heat Exchange," in Proceeding of the 41st Workshop on Geothermal Reservoir Engineering Stanford University, Stanford, California, Feb 2016.

Ichim, A., Teodoriu, C., and Falcone, G. (2018). Estimation of Cement Thermal Properties through the Three-phase Model with Application to Geothermal Wells. Energies 11 (10), 2839. doi:10.3390/en11102839

Kanev, K., Ikeuchi, J., Kimurat, S., and Okajima, A. (1997). Heat Loss to the Surrounding Rock Formation from a Geothermal Wellbore. Geothermics 26, 329-349. doi:10.1016/S0375-6505(96)00046-6

Li, X. Y., He, H. P., Duan, Y. Z., and Li, Y. F. (2017). Analysis on the Thermal Efficiency Improvement Process for Geothermal Well in Porous Sandstone. Oil Drilling Prod. Tech. 39 (4), 484-490. doi:10.13639/j. odpt.2017.04.016

Ma, B., Cao, Y., Wang, Y., Jia, Y., Qin, H. S., and Chen, Y. (2016). Origin of Carbonate Cements with Implications for Petroleum Reservoir in Eocene Sandstones, Northern Dongying Depression, Bohai Bay basin, China. Energy Exploration \& Exploitation 34 (2), 199-216. doi:10.1177/ 0144598716629871

Qomi, M. J. A., Bauchy, M., Ulm, F.-J., and Pellenq, R. J.-M. (2014). Anomalous Composition-dependent Dynamics of Nanoconfined Water in the Interlayer of Disordered Calcium-Silicates. J. Chem. Phys. 140 (5), 054515. doi:10.1063/1.4864118

Sarkar, P. K., and Mitra, N. (2021). Thermal Conductivity of Cement Paste: Influence of Macro-Porosity. Cement Concrete Res. 143, 106385. doi:10. 1016/j.cemconres.2021.106385

Tekin, S., and Akin, S. (2011). "Estimation of the Formation Temperature from the Inlet and Outlet Mud Temperatures while Drilling Geothermal Formations," in Proceedings of 36th Workshop on Geothermal Reservoir Engineering, Stanford (Stanford University).

Tóth, A. (2006). "Heat Losses in a Planned Hungarian Geothermal Power Plant," in Proceedings of the Thirsty-First Workshop on Geothermal Reservoir Engineering, Stanford, Feb 2016 (Stanford University).

Tylor, H. F. W. (1997). Cement Chemistry. London: Thomson Telford Publishers. doi:10.1680/cc.25929
Wang, G. L., Zhang, W., Liang, J. Y., Lin, W. J., and Wang, W. L. (2017). Evaluation of Geothermal Resources Potential in China. Acta Geoscientica 38 (04), 449-450+134+451. doi:10.3975/cagsb.2017.04.02

Won, J., Lee, D., Na, K., Lee, I.-M., and Choi, H. (2015). Physical Properties of G-Class Cement for Geothermal Well Cementing in South Korea. Renew. Energ. 80, 123-131. doi:10.1016/j.renene.2015.01.067

Yang, M., Meng, Y. F., Li, G., Deng, J. M., and Zhao, X. M. (2013). A Transient Heat Transfer Model of Wellbore and Formation during the Whole Drilling Process. Acta Petrolei Sinica 34 (2), 366-371. doi:10.7623/syxb201302021

Yang, T., Zhao, P., Li, Q., Zhao, Y., and Yu, T. (2021). Study on Thermophysical Properties of a Lead-Bismuth-Based Graphene Nanofluid. Front. Energ. Res. 9, 727447. doi:10.3389/fenrg.2021.727447

Zhao, J. (2020). Discussion on Technical Feasibility of Thermal Insulation Cement in Jiangsu Oilfield. Inner Mongolia Petrochemical Industry 3, 86-88. doi:10. 3969/j.issn.1006-7981.2020.11.032

Zhao, X. T., and Fu, H. Y. (2019). Analysis of Current Status and Prospects of Geothermal Energy Development and Utilization. Environ. Dev. 31 (5), 233. doi:10.16647/j.cnki.cn15-1369/X.2019.05.139

Zhou, F., and Zhang, X. (2013). Assessment of Heat Transfer in an Aquifer Utilizing Fractal Theory. Appl. Therm. Eng. 59 (1-2), 445-453. doi:10.1016/j. applthermaleng.2013.06.013

Conflict of Interest: The authors declare that the research was conducted in the absence of any commercial or financial relationships that could be construed as a potential conflict of interest.

Publisher's Note: All claims expressed in this article are solely those of the authors and do not necessarily represent those of their affiliated organizations, or those of the publisher, the editors, and the reviewers. Any product that may be evaluated in this article, or claim that may be made by its manufacturer, is not guaranteed or endorsed by the publisher.

Copyright (c) 2022 Zhang and Li. This is an open-access article distributed under the terms of the Creative Commons Attribution License (CC BY). The use, distribution or reproduction in other forums is permitted, provided the original author(s) and the copyright owner(s) are credited and that the original publication in this journal is cited, in accordance with accepted academic practice. No use, distribution or reproduction is permitted which does not comply with these terms. 